\title{
High Temperature Oxidation Behavior of High Nitrogen 9\%Cr Steels
}

\author{
Shoichi MATSUBARA, ${ }^{*}$ Tomiko YAMAGUCHI and Fujimitsu MASUYAMA \\ Department of Materials Science and Engineering, Kyushu Institute of Technology, 1-1, Sensui-cho, Tobata-ku, Kitakyushu, \\ 804-8550 Japan.
}

(Received on April 5, 2018; accepted on July 17, 2018)

\begin{abstract}
High temperature oxidation behavior of high nitrogen steel with about 0.3 mass $\%$ of nitrogen has been investigated comparing with nitrogen-free steels and ASME grade 91. High temperature oxidation tests were carried out in air over the temperature range 750 to $850^{\circ} \mathrm{C}$ for $300 \mathrm{~h}$ at maximum. Weight gain was measured and oxide scales were observed using an optical microscope and analyzed with an electron probe X-ray microanalyzer. It was found that the oxidation resistance of the high nitrogen steel is superior to that of nitrogen-free steels and ASME grade 91. Furthermore, $\mathrm{Cr}$ concentration in the oxide scale of the high nitrogen steel was higher than that in other steels. These results indicate high nitrogen promotes the formation of the oxide scale with high concentration of $\mathrm{Cr}$ inhibiting oxidation from proceeding in the high nitrogen steel.
\end{abstract}

KEY WORDS: high temperature oxidation; nitrogen; heat-resistant steel; ferritic steel; high nitrogen steel.

\section{Introduction}

The modern fossil-fired thermal power plants are presently operated at the steam temperature of $600^{\circ} \mathrm{C}$. Nevertheless, there is a growing demand for reducing the $\mathrm{CO}_{2}$ emission from the perspective of resources and energy conservation. To meet the demand, further increasing of steam temperature up to $700^{\circ} \mathrm{C}$ is expected for the significant improvement of thermal efficiency. To further enhance thermal efficiency materials which are able to withstand higher temperature and pressure are essential, and the development of heat-resistant ferritic steels having exceptional elevated temperature performance is sorely needed. The use of existing creep strength enhanced ferritic steels such as ASME grades 91,92 and 122 is limited to around $630^{\circ} \mathrm{C}$ in terms of high temperature strength and oxidation resistance. ${ }^{1)}$ Consequently, the appearance of ferritic steels standing up to higher temperature is strongly desired. Under the state, the addition of high nitrogen to ferritic steels is attracting considerable attention because of improving high temperature strength and oxidation resistance of them. There have been several investigations ${ }^{2-4}$ on the effect of adding high nitrogen to ferritic steels on their properties. Their studies have reported improvement of creep strength and oxidation resistance by high nitrogen; however a quantitative evaluation and a comprehensive understanding of the effect of nitrogen on oxidation resistance are still lacking. Better understanding about high temperature oxidation behavior of high nitrogen ferritic steels is needed for applications in future advanced fossil-fired thermal power plants. This

\footnotetext{
* Corresponding author: E-mail: m110058s@mail.kyutech.jp DOI: https://doi.org/10.2355/isijinternational.ISIJINT-2018-246
}

work was done to evaluate the oxidation resistance of high nitrogen steels and to investigate the effect of nitrogen on oxidation resistance using high nitrogen steels with about $0.3 \%$ nitrogen manufactured by means of Pressurized Electro-Slag Remelting (PESR) method, nitrogen-free steels and ASME grade 91.

\section{Experimental}

Throughout this paper the composition of specimen is expressed in mass percent. For high temperature oxidation test, high nitrogen $9 \% \mathrm{Cr}$ steel (HN9) with about $0.3 \%$ nitrogen, nitrogen-free 9\% Cr steels (FN9 and FN9C) and 9\% Cr martensitic commercial steel (ASME grade 91, hereafter called Gr.91) are prepared. The chemical compositions of the test materials are shown in Table 1. The difference of the compositions between high nitrogen steel and nitrogenfree steels is only the amount of nitrogen. Furthermore, HN9, FN9C and Gr.91 fully consist of tempered martensite, while FN9 is composed of ferrite. The microstructure of all steels tested is shown in Fig. 1. Comparing HN9 (high nitrogen steel) with FN9 (nitrogen-free steel), the effect of high nitrogen on high temperature oxidation resistance of $9 \% \mathrm{Cr}$ ferritic steels was investigated under same chemical composition except nitrogen. In addition comparing HN9 (high nitrogen steel) with FN9C (nitrogen-free steel) the influence of high nitrogen on high temperature oxidation resistance was studied under same microstructure of martensite since FN9 (nitrogen-free steel) consists of ferritic structure. All test materials were machined out to the plates measuring $12 \mathrm{~mm}$ by $12 \mathrm{~mm}$ with $3 \mathrm{~mm}$ thickness. Then, the specimens were polished by $\mathrm{SiC}$ paper (\#600), and cleaned ultrasonically in acetone and dried in air at $40^{\circ} \mathrm{C}$ for $1 \mathrm{~h}$ 
Table 1. Chemical composition of test materials.

\begin{tabular}{ccccccccccccc}
\hline \multicolumn{1}{c}{ Steels } & $\mathrm{N}$ & $\mathrm{C}$ & $\mathrm{Si}$ & $\mathrm{Mn}$ & $\mathrm{Ni}$ & $\mathrm{Cr}$ & $\mathrm{Co}$ & $\mathrm{W}$ & $\mathrm{Mo}$ & $\mathrm{V}$ & $\mathrm{Nb}$ \\
\hline HN9 & 0.32 & 0.010 & 0.08 & 0.07 & 0.01 & 9.06 & 4.00 & 5.97 & 1.04 & 0.60 & 0.02 \\
FN9 & 0.0020 & 0.010 & 0.06 & 0.07 & 0.02 & 9.00 & 3.90 & 5.82 & 1.01 & 0.62 & 0.02 \\
FN9C & 0.0020 & 0.25 & 0.06 & 0.07 & 0.02 & 9.00 & 3.90 & 5.82 & 1.01 & 0.62 & 0.02 \\
Gr.91 & 0.044 & 0.09 & 0.26 & 0.44 & 0.13 & 8.29 & - & - & 0.88 & 0.2 & 0.1 \\
\hline
\end{tabular}
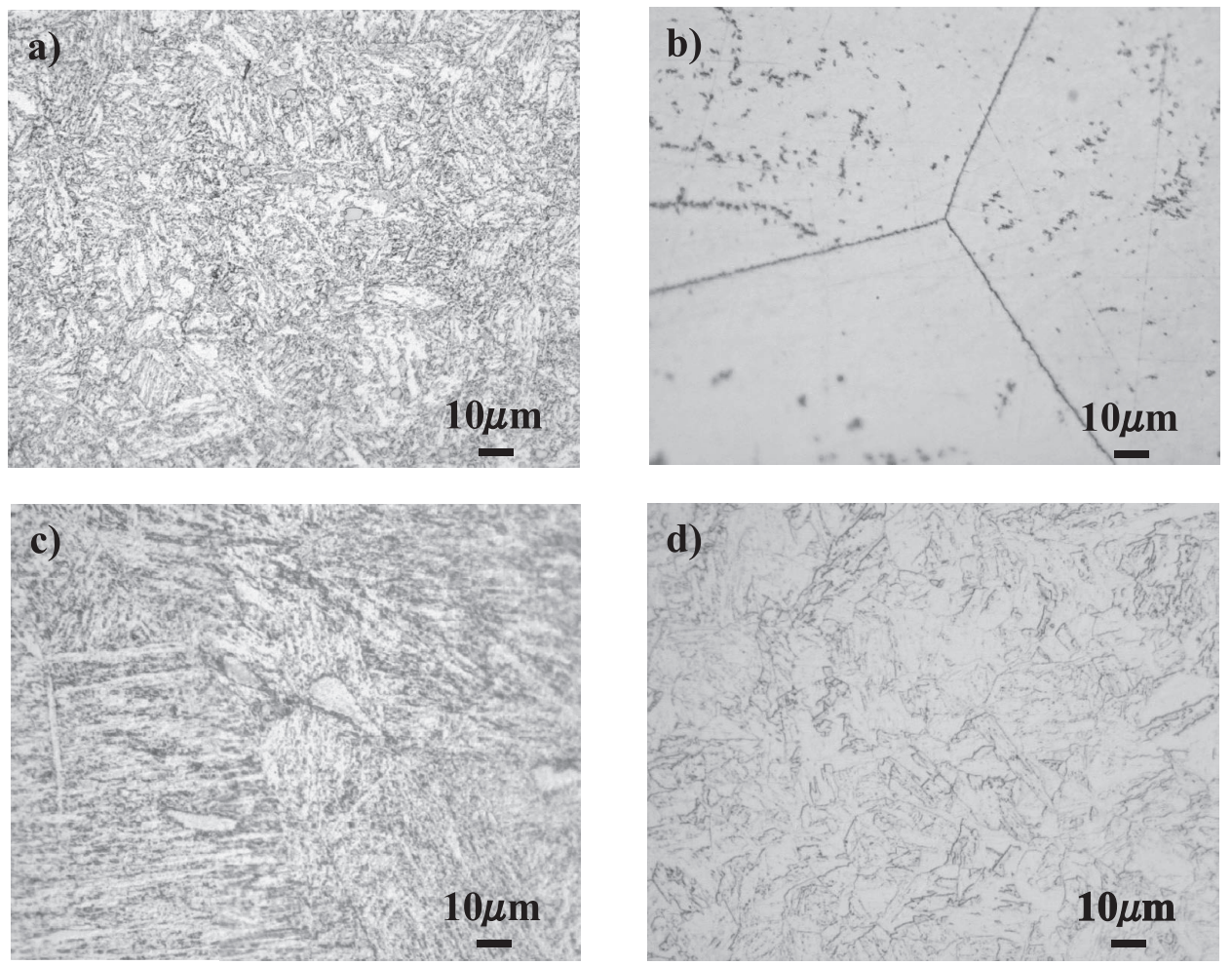

Fig. 1. Microstructure of test materials: a) HN9 (high nitrogen steel), b) FN9 (nitrogen-free steel), c) FN9C (nitrogenfree steel) and d) Gr. 91 (commercial steel).

in order to remove grease. The procedure adopted in this study was essentially the same as that described in previous study. ${ }^{2)}$ After that the test specimens were placed in alumina crucibles $\left(95 \% \mathrm{Al}_{2} \mathrm{O}_{3}-5 \% \mathrm{SiO}_{2}\right)$ and high temperature oxidation test were carried out in a muffle furnace. The test conditions were as follows, atmosphere; air, temperature; 750 to $850^{\circ} \mathrm{C}$, and time; 30 to $300 \mathrm{~h}$. Measurements of weight of specimens before and after test were conducted and oxide scales were observed with an optical microscope (OM) and an scanning electron microscope (SEM) and analyzed with an electron probe X-ray microanalyzer (EPMA).

\section{Results and Discussion}

\subsection{High-temperature Oxidation Behavior}

Figure 2 provides a bar graph of weight gain against temperature. For FN9 and FN9C (nitrogen-free steel) the weight gain increased abruptly from 750 to $800^{\circ} \mathrm{C}$, above which it increased gradually. In contrast the weight gain of HN9 (high nitrogen steel) showed a gradual rise from 750 to $850^{\circ} \mathrm{C}$. From this figure it can be deduced that improvement in oxidation resistance for ferritic heat-resistant steel is achieved up to $850^{\circ} \mathrm{C}$ by the addition of high nitrogen. Gr.91 (commercial steel) exhibited an anomalous tem- perature dependence of the oxidation behavior. The weight gain did not increase as temperature increased and had a minimum at $800^{\circ} \mathrm{C}$. For some ferritic steels the weight gain shows anomalous temperature dependence owing to the change of the diffusion rate of element such as $\mathrm{Cr}$ and $\mathrm{Si}$ which suppress the oxidation proceeding. ${ }^{5)}$ The anomalous temperature dependence of the oxidation behavior seen in the commercial steel are attributed to a sufficient supply of $\mathrm{Cr}$ from the substrate steel at $800^{\circ} \mathrm{C}$.

Figure 3 shows weight gain changes with time at $800^{\circ} \mathrm{C}$ for 30 to $300 \mathrm{~h}$. The behavior of all steels obeyed the parabolic law. The weight gain of all steels increased as holding time increased. The weight gain of HN9 (high nitrogen steel) increased gradually with an increase in holding time, whereas that of FN9 and FN9C nitrogen-free steel increased abruptly with increasing holding time. The weight gain of Gr.91 (commercial steel) showed a gradual increase and the degree of the weight gain change was relatively high compared to that of the high nitrogen steel. From these results it is revealed that the addition of high nitrogen to ferritic steels attributes high temperature oxidation resistance of them to be enhanced considerably. Since the behavior of all steels obeys the parabolic law at $800^{\circ} \mathrm{C}$ square of weight gain is plotted against time in Fig. 4. As a rule the behavior of 

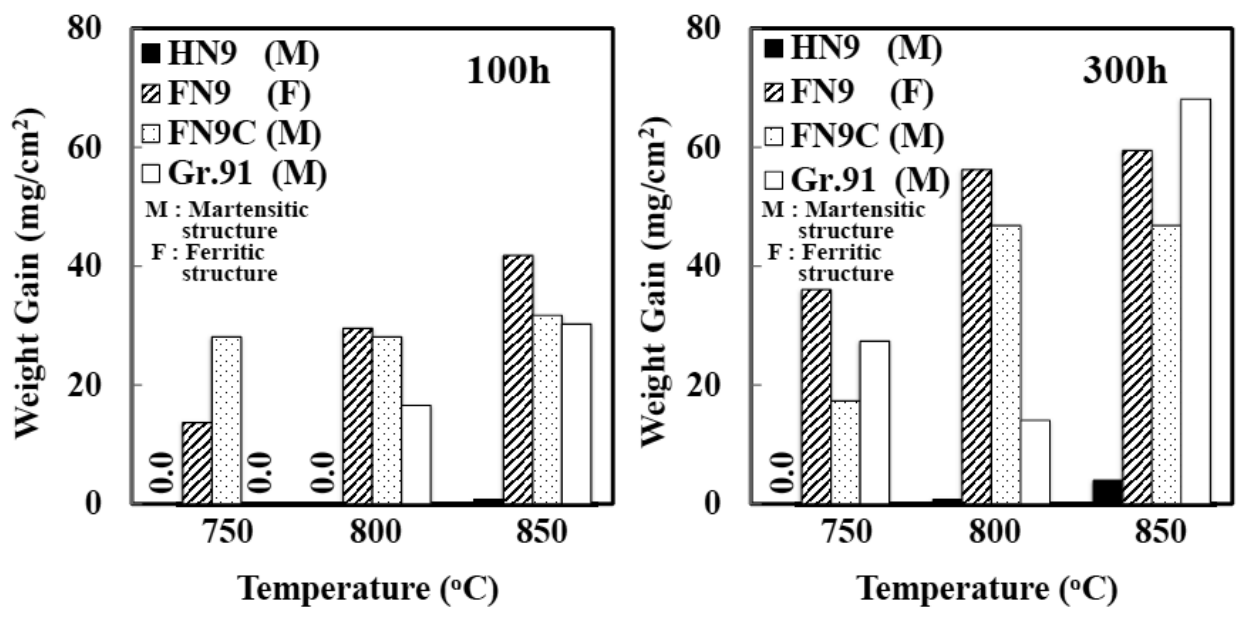

Fig. 2. Effect of temperature on weight gain of steels tested.

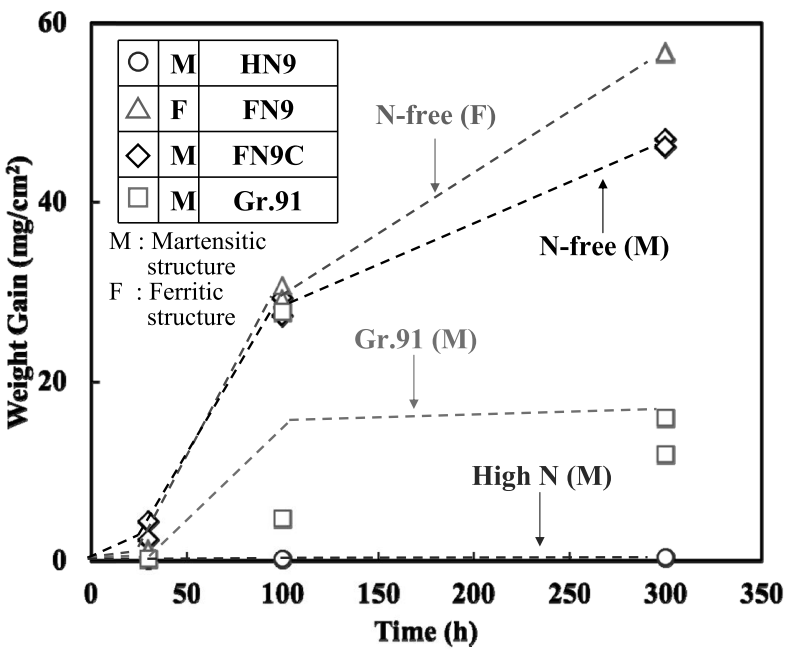

Fig. 3. Weight gain changes with time at $800^{\circ} \mathrm{C}$ for 30 to $300 \mathrm{~h}$.

high temperature oxidation of metals obeys parabolic law. Therefore the parabolic rate constant $K_{p}\left(\mathrm{mg}^{2} \mathrm{~cm}^{-4} \mathrm{~h}^{-1}\right)$ can be obtained by following equation.

$$
(\Delta W)^{2}=K_{p} t
$$

where, $\Delta W\left(\mathrm{mg} \mathrm{cm}^{-2}\right)$ is weight gain change and $t(\mathrm{~h})$ time. Using Eq. (1) we obtained the parabolic rate constants for all steels which are listed in the table in Fig. 4. The parabolic rate constant of high nitrogen steel was smaller than that of other steels. From a comparison of the value of parabolic rate constant obtained, it can be said that high nitrogen ferritic steel has excellent high temperature oxidation resistance. The behavior of all steels obeyed the parabolic law at $750^{\circ} \mathrm{C}$ and $850^{\circ} \mathrm{C}$ also. The parabolic rate constants at $750^{\circ} \mathrm{C}$ and $850^{\circ} \mathrm{C}$ were calculated as at $800^{\circ} \mathrm{C}$. The constants obtained are plotted against the reciprocal of the absolute temperature in Fig. 5. Moreover the values of frequency factor $A\left(\mathrm{mg}^{2} \mathrm{~cm}^{-4} \mathrm{~h}^{-1}\right)$ and activation energy $Q\left(\mathrm{j} \mathrm{mol}^{-1}\right)$ are provided by the following Arrhenius' rate equation.

$$
K_{p}=A e^{-Q / R T}
$$

where, $A$ is the frequency factor, $Q$ the activation energy, $\mathrm{R}\left(\mathrm{j} \mathrm{k}^{-1} \mathrm{~mol}^{-1}\right)$ the gas constant and $\mathrm{T}(\mathrm{K})$ the absolute temperature. The values of frequency factor $A$ and activation energy $Q$ obtained from Eq. (2) are listed in Table 2.

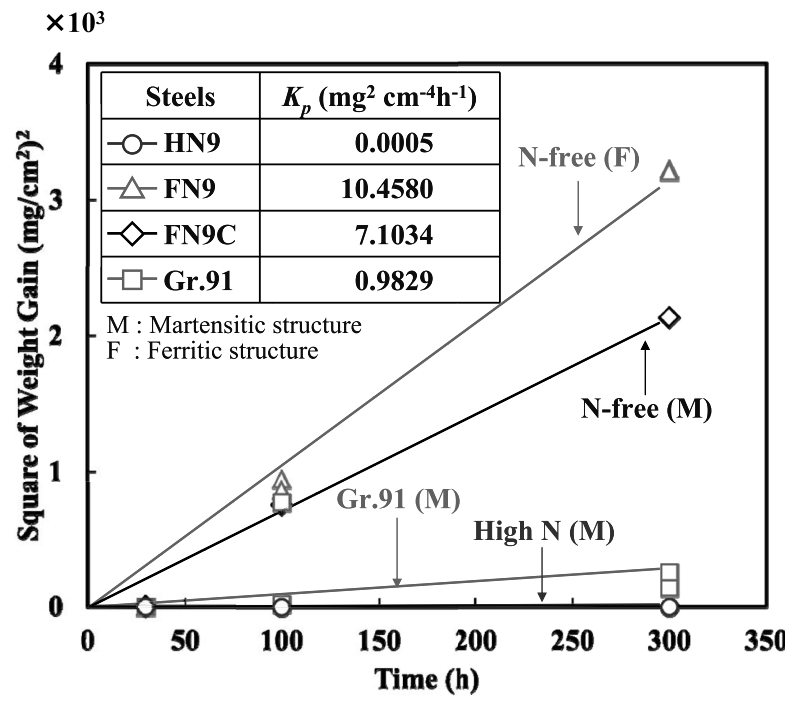

Fig. 4. Square of weight gain plotted against time at $800^{\circ} \mathrm{C}$ for 30 to $300 \mathrm{~h}$.

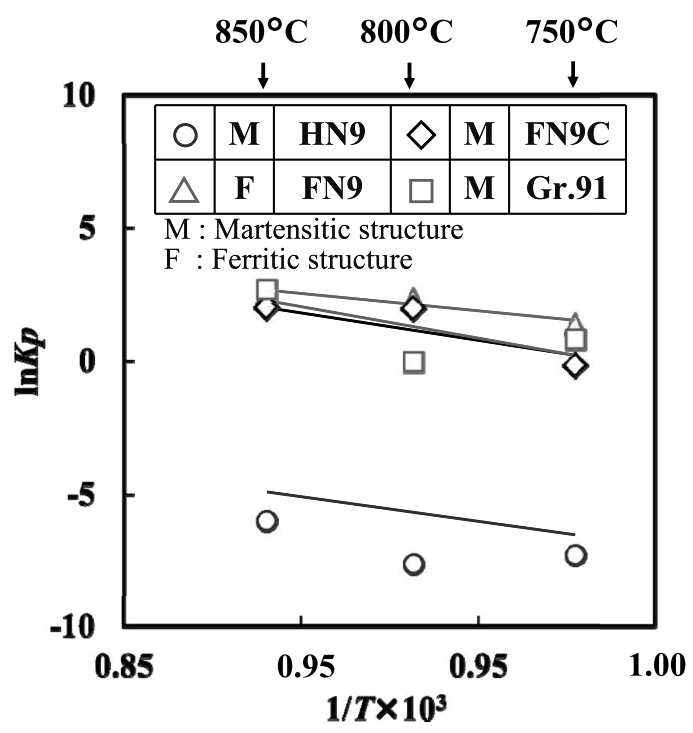

Fig. 5. Arrhenius plot of parabolic rate constant.

It should be noted that the value of frequency factor of HN9 (high nitrogen steel) is smaller than those of other steel. This result agrees with previous result. ${ }^{2)}$ The frequency factor was obtained from the parabolic rate constant from 750 to 
$850^{\circ} \mathrm{C}$. The parabolic rate constant was calculated on condition that the oxidation behavior of all steels tested obeys the parabolic law. In this sense, it is valid that the Arrhenius plot clealy distinguish the superior oxidation resistance of high nitrogen steel with extremely low frequency factor, but not activation energy as properly plooted in Fig. 5. When the oxidation behavior of metals obeys the parabolic law the high temperature oxidation reaction is restricted by the diffusion of oxide ion and metals ion through oxide scale formed. ${ }^{6}$ Therefore the above result and previous result is considered to be due to the difference of diffusion rate of oxide ion or metals ion between high nitrogen steels and nitrogen-free steels.

From the industrial point of view it is needed to quantitatively evaluate of the effect of high nitrogen on high temperature oxidation for $9 \% \mathrm{Cr}$ steels. Then weight gain at $800^{\circ} \mathrm{C}$ for 30 to $300 \mathrm{~h}$ based on this work and previous work $^{2)}$ which is provided as plots of weight gain of HNS (High Nitrogen Steel) and Gr.92 (commercial steel) is plotted against $\mathrm{N}$ content in Fig. 6. The weight gain of $9 \% \mathrm{Cr}$ steels showed a positive $\mathrm{N}$ content dependence. The weight gain of $9 \% \mathrm{Cr}$ steels decreased appreciably with increasing $\mathrm{N}$ content at any time measured. Furthermore the weight

Table 2. Frequency factor A and activation energy $Q$ of tested steels.

\begin{tabular}{ccc}
\hline Steels & $Q\left(\mathrm{~kJ} \mathrm{~mol}^{-1}\right)$ & $\ln A\left(\mathrm{mg}^{2} \mathrm{~cm}^{-4} \mathrm{~h}^{-1}\right)$ \\
\hline HN9 (High nitrogen steel) & 118 & 6.36 \\
FN9 (Nitrogen-free steel) & 108 & 14.19 \\
FN9C (Nitrogen-free steel) & 208 & 24.69 \\
Gr.91 (Commercial steel) & 166 & 20.48 \\
\hline
\end{tabular}
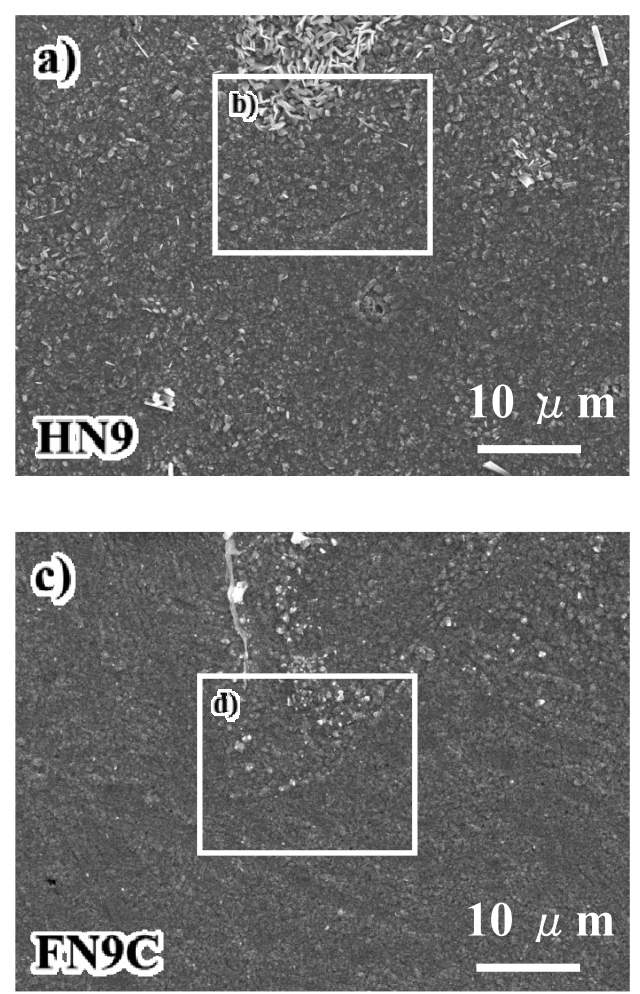

gain of the high nitrogen steels increased slightly as time increased, whereas that of nitrogen-free steels and commercial steels increased sharply. This finding leads to a conclusion that the high temperature oxidation resistance of $9 \% \mathrm{Cr}$ heat-resistant steels depends greatly on the $\mathrm{N}$ contents. To improve the oxidation resistance of ferritic steels compared with commercial steel, it is needed to add more high nitrogen than that of commercial steels.

\subsection{Characteristics of the Oxide Scale}

Figure 7 shows the features of the oxide surface of HN9 (high nitrogen steel) and FN9C (nitrogen-free steel) oxidized at $700^{\circ} \mathrm{C}$ for $0.5 \mathrm{~h}$. The oxide scale of HN9 consisted of granular oxides and flakey oxide. The size of granular oxides was smaller than that of flaky oxides. In contrast

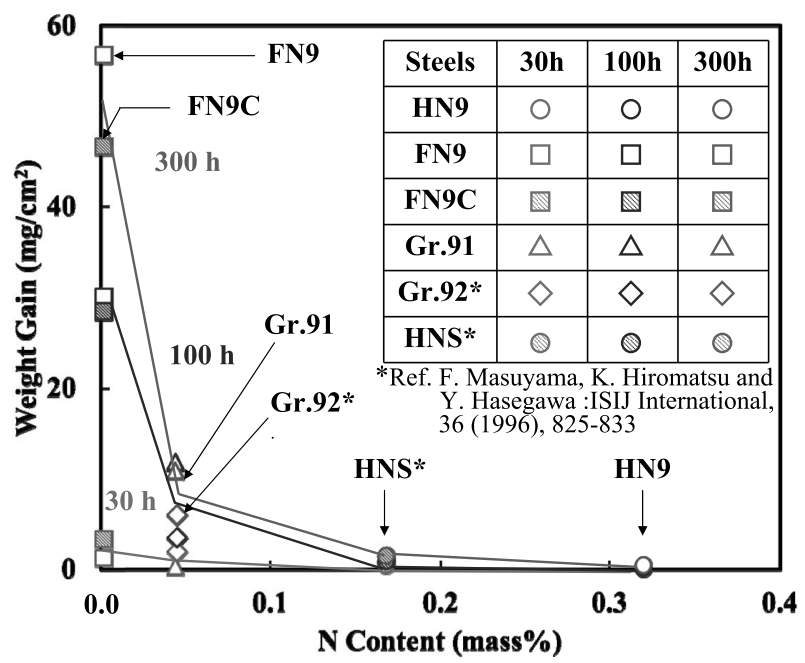

Fig. 6. Effect of $\mathrm{N}$ content on weight gain at $800^{\circ} \mathrm{C}$ for 30 to $300 \mathrm{~h}$.
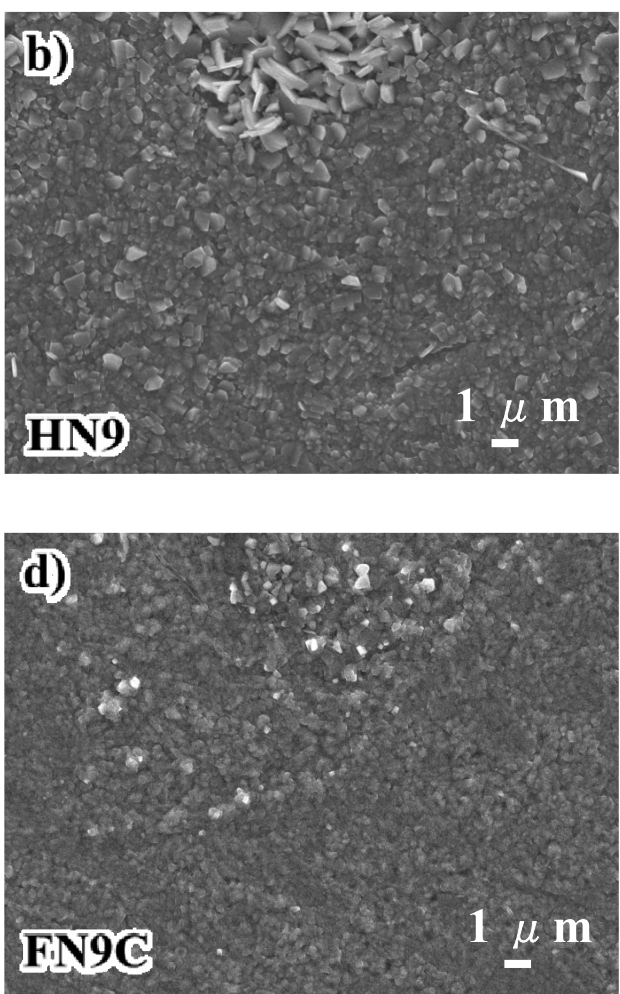

Fig. 7. SEM image of HN9 and FN9C oxidized at $700{ }^{\circ} \mathrm{C}$ for $0.5 \mathrm{~h}$ in air showing features of the surface of oxide scale: a) surface of HN9 (high nitrogen steel) and c) surface of FN9C (nitrogen-free steel). 
the oxide scale of FN9C was composed of granular oxides. There was no appreciable difference between the sizes of oxides of both steels at early stage of oxidation. Figure 8 showes element distributions in the oxide scale surface of $\mathrm{HN} 9$ and FN9C oxidized at $700^{\circ} \mathrm{C}$ for $0.5 \mathrm{~h}$. No great difference between the $\mathrm{Cr}$ concentrations of both steels was seen in the surface of oxide scale, but the concentration of Fe of HN9 was smaller than that of FN9C in the surface of oxide. These fact indicates that oxides with $\mathrm{Fe}$ is not formed more easily in high nitrogen steel than in nitrogen-free steel from early stage of oxidation. In addition, examination of the surface of oxides by EPMA revealed that the flaky oxides observed in HN9 were mainly composed of V, Fe and O.

Figure 9 shows the cross-sectional microstructure of oxide scale of all steels heated at $800^{\circ} \mathrm{C}$ for $300 \mathrm{~h}$ in air.
Examination of the oxide scale by optical microscope revealed that the oxide scale thickness of HN9 (high nitrogen steel) was extremely thinner than that of other steels. From this observation of oxide scale it can be stated that the high nitrogen steel shows the excellent high temperature oxidation resistance comparing to nitrogen-free steels and the commercial steel. The oxide scale of HN9 (high nitrogen steel) showed an appearance of one layer structure. In contrast, the oxide scale of FN9 and FN9C (nitrogen-free steels) and Gr.91 (commercial steel) was composed of two layer structure, which is outer scale and inner scale. The oxide scale on FH9, FN9C and Gr.91 specimens almost uniformly formed, but the thickness of the oxide scale was sometimes irregular depending on the formation of void or crack in the oxide scale. Furthermore analysis of the scale

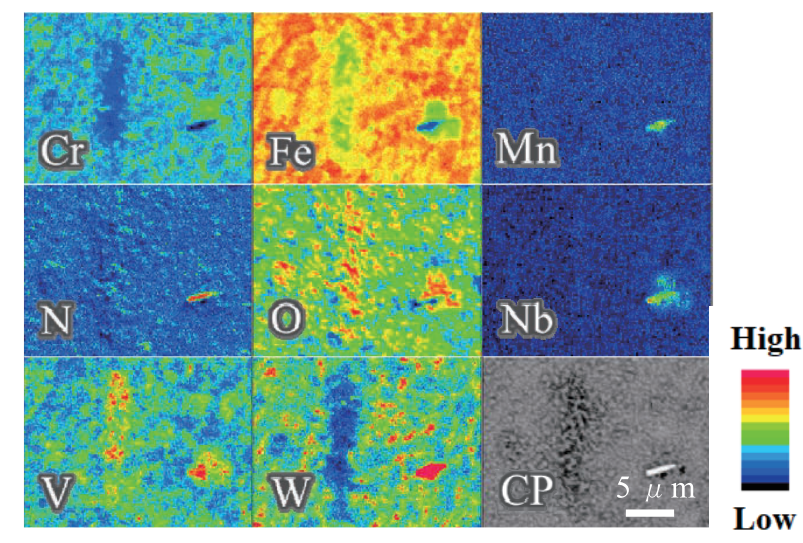

a) HN9 (High nitrogen steel)

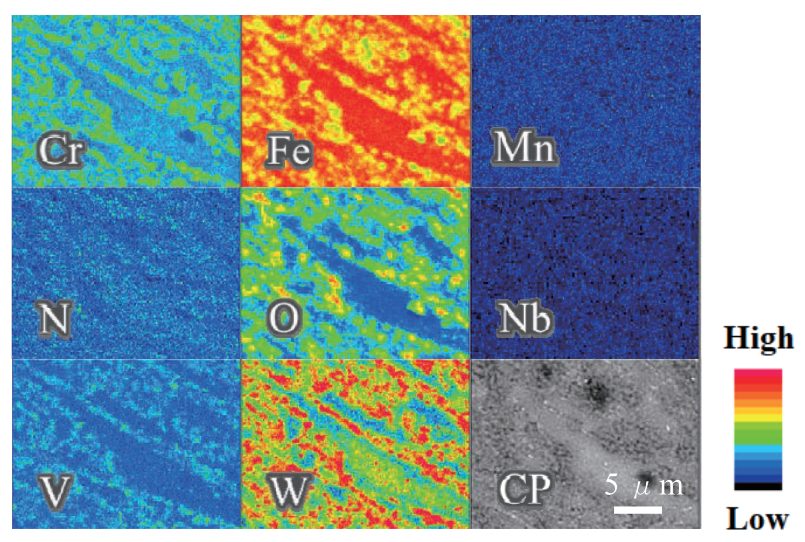

b) FN9C (Nitrogen-free steel)

Fig. 8. Element distribution in the surface of oxide scale of $\mathrm{HN} 9$ and FN9C oxidized at $700^{\circ} \mathrm{C}$ for $0.5 \mathrm{~h}$ in air: a) $\mathrm{HN} 9$ (high nitrogen steel) and b) FN9C (nitrogen-free steel).
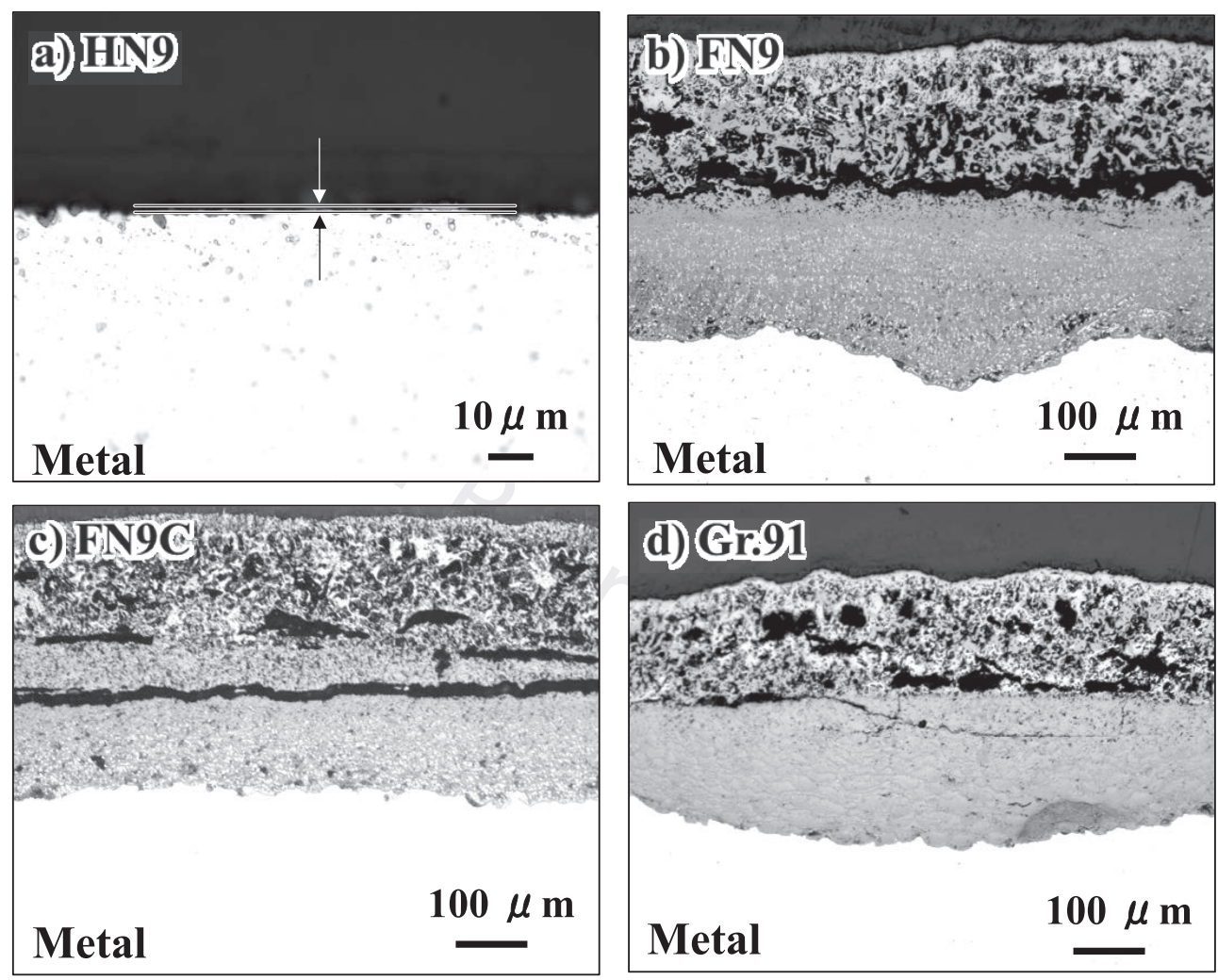

Fig. 9. Cross-sectional microstructure of oxide scale of tested steels after oxidation at $800^{\circ} \mathrm{C}$ for $300 \mathrm{~h}$ in air: $\mathrm{HN} 9$ (high nitrogen steel) and b) FN9 (nitrogen-free steel), c) FN9C (nitrogen-free steel) and 4) Gr.91 (commercial steel). 
by EPMA revealed the difference of element distribution in oxide scale between high nitrogen steel, nitrogen-free steel and commercial steel. As shown in Fig. 9 the thickness of oxide scale of the high nitrogen steel was different from that of nitrogen-free steels. Thus to analyze the oxide scale of all steels under same magnification by EPMA the analysis was conducted on the whole scale for high nitrogen steel and the inner scale for other steels. The element distribution in oxide scale of all steels heated at $800^{\circ} \mathrm{C}$ for $300 \mathrm{~h}$ in air is shown in Fig. 10 and the changes in element concentration from oxide surface to metal are provided in Fig. 11. The oxide of high nitrogen steels mainly consisted of $\mathrm{Fe}$ and $\mathrm{Cr}$ with one layer structure and in the oxide scale the concentration of $\mathrm{Cr}$ was higher than $\mathrm{Fe}$. In the oxide scale of the nitrogen-free steel (FN9 and FN9C) and commercial steel (Gr.91) the inner layer scale was mainly composed of $\mathrm{Fe}$ and $\mathrm{Cr}$ whereas the outer layer scale mainly consisted of $\mathrm{Fe}$. It should be noted that the $\mathrm{Cr}$ concentration is high in the oxide of high nitrogen steel. This high $\mathrm{Cr}$ concentration observed in the oxide scale of high nitrogen steel is not reported by previous study. ${ }^{2)}$ The previous work has reported that the intensified oxidation resistance of high nitrogen steel is attributable to a tendency toward smaller decrease of $\mathrm{Cr}$ concentration at the metal surface comparing with commercial steel. This discrepancy can be explained by the difference of the condition investigated between this paper and previous one. In the study, element distributions were analyzed at the condition that the oxide thickness of high nitrogen steel is extremely smaller than other steels. In contrast, in previous work analyses of element distributions were mainly carried out at the condition that the oxide thickness of high nitrogen steel is as same as comparative steel. Considering the result obtained in this research, the excellent oxidation resistance shown in high nitrogen steel is considered to be a result of enriched $\mathrm{Cr}$ in the oxide scale. This indicates the addition of high nitrogen plays a critical role in forming the oxide scale involving incredibly high concentration of $\mathrm{Cr}$.

As shown in Fig. 5, the frequency factor of oxidation reaction in the high nitrogen steel was smaller than that of other steels. We suggested that the above result is due to the diffusion rate of oxide ion or metals ion. And it is considered that nitrogen may strongly affect to the absorption of oxygen ion and/or formation of oxidation film. It is known that in the oxide scale diffusion rate of these ions change by the kind of element composing oxide scale. $\left.{ }^{6}\right)$ The oxidation reaction rate of the oxide composed of $\mathrm{Al}$ or $\mathrm{Cr}$ is smaller than that of $\mathrm{Fe}$, and this is because the diffusion rate of ions in the Al-oxide or Cr-oxide is greatly smaller than that in the Fe-oxide. In addition, it is known that the oxidation resistance of ferritic heat-resistant steels is improved by an increase in $\mathrm{Cr}$ content of the steels. ${ }^{5}$ In general $\mathrm{Cr}$ concentration in the oxide scale increases with an increase in $\mathrm{Cr}$ content. The increase in $\mathrm{Cr}$ concentration in the oxide scale suppresses the diffusion of metals, resulted
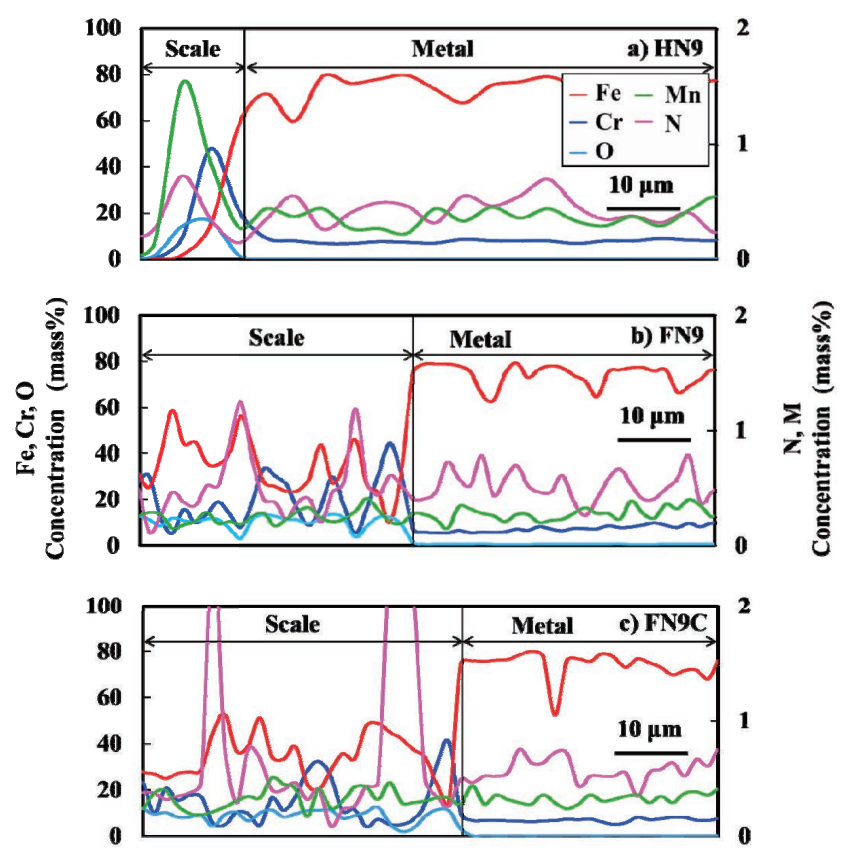

Disstance $(\mu \mathrm{m})$

Fig. 11. Element distribution in oxide scale of tested steels after oxidation at $800^{\circ} \mathrm{C}$ for $300 \mathrm{~h}$ in air: a) HN9 (high nitrogen steel), b) FN9 (nitrogen-free steel) and FN9C (nitrogen-free steel).

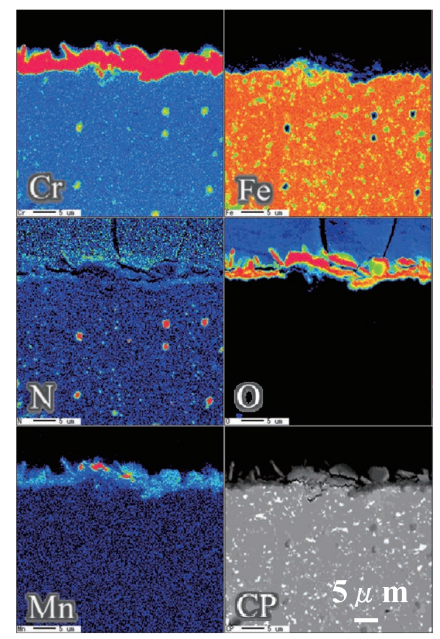

a) HN9 (High nitrogen steel)

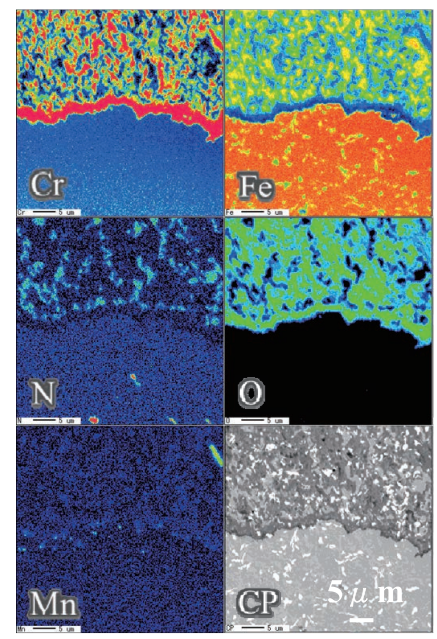

b) FN9 (Nitrogen-free steel)

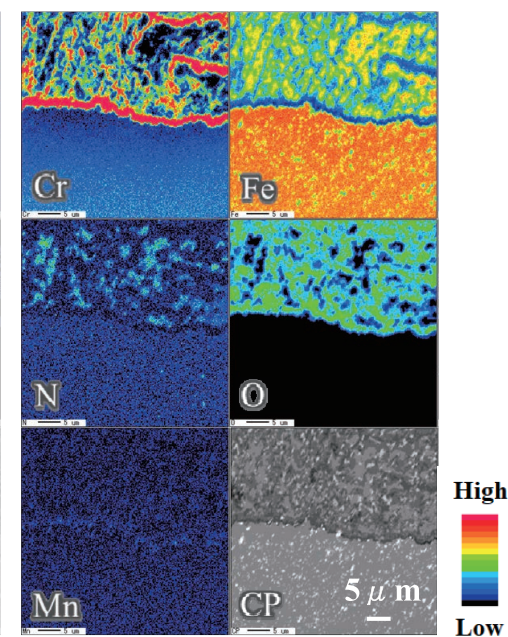

c) FN9C (Nitrogen-free steel)

Fig. 10. Element distribution in oxide scale of tested steels after oxidation at $800^{\circ} \mathrm{C}$ for $300 \mathrm{~h}$ in air: a) $\mathrm{HN} 9$ (high nitrogen steel), b) FN9 (nitrogen-free steel) and c) FN9C (nitrogen-free steel). 
in the improving the oxidation resistance. A previous work has reported that the oxide scale of $12 \% \mathrm{Cr}$ steels involves high $\mathrm{Cr}$ concentration in the oxide scale comparing with $9 \% \mathrm{Cr}$ and $2 \% \mathrm{Cr}$ steels. ${ }^{7)}$ The frequency factor of oxidation reaction in ferritic steel decreases as the $\mathrm{Cr}$ content increases. Considering above knowledge and previous work, it is a reasonable assumption that the decrease of frequency factor of oxidation reaction in the high nitrogen steel can be described in terms of the oxide scale formed involving high Cr concentration.

\section{Conclusions}

High temperature oxidation behavior of high nitrogen steel with about 0.3 mass $\%$ of nitrogen has been investigated in the temperature range 750 to $850^{\circ} \mathrm{C}$ for $300 \mathrm{~h}$ at maximum, comparing with nitrogen-free steels and ASME grade 91 . The main results obtained are shown below.

(1) Weight gain of the high nitrogen steel was extremely smaller than that of nitrogen-free steels and commercial steel. The addition of high nitrogen to ferritic heat-resistant steels greatly improves the high temperature oxidation resistance of those.

(2) The oxidation behavior of the high nitrogen steel obeyed the parabolic law, and the frequency factor of the high nitrogen steel in high temperature oxidation reaction was significantly smaller than that of nitrogen-free steels. The smaller frequency factor of the high nitrogen steel is attributed to the $\mathrm{Cr}$-rich protective oxide scale formed on the steel decreasing the diffusion rate of metal ions.

(3) For $9 \% \mathrm{Cr}$ ferritic steels the oxidation resistance depended on the $\mathrm{N}$ content: the weight gain of ferritic steels after oxidation test decreases as the $\mathrm{N}$ content increases.

(4) The oxide scale of the high nitrogen steel was thinner than that of other $9 \% \mathrm{Cr}$ steels and showed an appearance of one layer. The oxidation scale consisted of $\mathrm{Fe}$ and $\mathrm{Cr}$, and the concentration of $\mathrm{Cr}$ was incredibly higher than that of Fe. From this, it is concluded that the addition of high nitrogen promotes the formation of protective oxide scale having high $\mathrm{Cr}$ resulting in the excellent oxidation resistance of the high nitrogen steel.

\section{Acknowledgments}

This work was performed as a part of the research activities of Advanced Low Carbon Technology Research and Development Program. The authors acknowledge the financial support by Japan Science and Technology Agency to this project under JST ALCA rant Number JPMJAL1101 and discussion with the members of this project.

\section{REFERENCES}

1) F. Masuyama: ISIJ Int., 41 (2001), 612.

2) F. Masuyama, K. Hiromatsu and Y. Hasegawa: ISIJ Int., 36 (1996), 825.

3) P. Uggowitzer, B. Anthamatten, M. Speidel and G. Stein: Advances in Materials Technology for Fossil Power Plants, ASM International, Metals Park, OH, (1987), 181.

4) S. Komazaki: Mater. Sci. Eng. A, 676 (2016), 100.

5) P. Ennis and W. J. Quadakkers: Int. J. Press. Vessel. Pip., 84 (2007), 75.

6) N. Birks, G. Meier and F. Pettit: Introduction to the High-Temperature Oxidation of Metals, Cambridge University Press, New York, (2006), 63.

7) Y. Fukuda, T. Sato and K. Tamura: Report of the 123rd Committee on Heat Resisting Metals and Alloys, Vol. 39, JSPS, Tokyo, (1998), 379. 